\title{
A "democracia popular" da Frente Sandinista de Libertação Nacional: uma breve discussão a partir do debate marxista e da práxis revolucionária
}

\author{
Stella Ferreira Gontijo ${ }^{1}$
}

\begin{abstract}
Resumo: Neste artigo nos propomos a realizar um debate inicial sobre o conceito de democracia defendido pelos sandinistas, buscando compreender de que forma este se relaciona a uma discussão do marxismo acerca da hegemonia e da tomada de consciência revolucionária. Para isso, consideramos a singularidade do processo sandinista, que por meio da luta armada toma o poder na Nicarágua em 1979, no contexto pós-Revolução Cubana (1959), adotando uma perspectiva revolucionária própria, que tem a democracia como eixo central para se alcançar a soberania nacional e popular. Para compreendermos o projeto democrático sandinista e a disputa da hegemonia empreendida pela Frente Sandinista de Libertação Nacional, recorremos não apenas aos documentos da Frente, mas a estabelecer a relação dessas definições com o debate mais amplo do marxismo, principalmente gramsciano, a partir da historicidade latinoamericana.
\end{abstract}

Palavras-chave: Revolução Sandinista; democracia popular; esquerdas latino-americanas.

\section{The "popular democracy" from the Frente Sandinista de Liebración Nacional: a brief discussion from inside the marxism debate and the revolutionary praxis}

\begin{abstract}
In this article, we propose to establish an initial debate on the concept of democracy defended by the Sandinists, seeking to understand how these definitions are related to the Marxism discussion on hegemony and revolutionary awareness. For this purpose, we considered the singularity of the Sandinist process, which through armed struggle took power in Nicaragua in 1979, under the influence of the Cuban Revolution (1959), adopting its own revolutionary perspective, in which democracy is at the center of achieving national and popular sovereignty. To comprehend the project of democracy and hegemony dispute undertaken by the FSLN, we use the official documents, but also the Marxist debate, mainly from Gramsci, from Latin American historicity.
\end{abstract}

Keywords: Sandinist Revolution; popular democracy; latin-american left.

Artigo recebido em: 27/01/2020

Artigo aprovado para publicação em: 20/04/2020

1 Doutoranda em História pela Universidade Federal de Minas Gerais, com pesquisa sob o título "Produção intelectual e trajetória de Margaret Randall: o debate transnacional de uma teoria política feminista latinoamericana (1962 - 1984)", com orientação da Profa. Dra. Adriane Vidal Costa. Bolsista CNPq. E-mail: sfgontijo@gmail.com. 


\section{Introdução}

No presente trabalho pretendemos discutir como se caracterizava o conceito de democracia, ou da chamada "democracia popular", adotado pela Frente Sandinista de Libertação Nacional (FSLN), na Nicarágua, na segunda metade do século XX. Buscaremos relacionar tal definição ao debate marxista mais amplo sobre o tema, para um embasamento teórico que aproxime a experiência nicaraguense das discussões propostas pelo marxismo Ocidental. Nesse caso, nossa principal referência é Gramsci, importante teórico que oferece uma perspectiva renovada ao marxismo, e que chega a ser citado pelos teóricos sandinistas. Não pretendemos aqui fazer um resgate histórico do uso do conceito da democracia, que foi um dos eixos centrais da teoria revolucionária sandinista, nem retomaremos a trajetória política e produção intelectual de Antônio Gramsci, trabalho que seria inviável devido à dimensão da pesquisa exigida, algo que escapa ao nosso objetivo. Sendo assim, não nos propomos a voltar ao sandinismo dos anos 1920/30, a Sandino ${ }^{2}$, para buscarmos a possível origem da ideia de “democracia popular", adotada pelos sandinistas a partir da década de 1960, ou muito menos discutirmos as várias facetas desse conceito, o que nos levaria à democracia ateniense.

Temos como objetivo compreender qual era a "democracia popular" defendida pelos sandinistas, de que forma esta se relacionava, principalmente, aos conceitos de hegemonia e nacional-popular de Gramsci; como a implementação desse tipo de democracia dizia respeito à ampliação da participação política, com a emergência de novos sujeitos sociais e, por fim, as contradições com a democracia burguesa e o caminho para derrocada do processo revolucionário. Para isso, consideramos importante realizar uma análise do Programa Histórico

\footnotetext{
2 Sandino é um herói nacional da Nicarágua, considerado como "o general de homens livres", inspirador da Frente Sandinista de Libertação Nacional e da Revolução de 1979. Nos anos 1930, defendeu a independência nacional da Nicarágua, o anti-imperialismo, o internacionalismo e o centro-americanismo. Para ele, os problemas de seu povo só poderiam ser resolvidos pela Revolução popular. Luta contra os liberais conservadores, a Igreja Católica e os EUA, pelo fim da intervenção norte-americana na Nicarágua, representada pela presença dos marines. Com a retirada dos marines os EUA organizam a Guarda Nacional comandada por Somoza. Para Mires (2001), o assassinato de Sandino em 1934, o massacre das colônias agrícolas que ele havia fundado por parte da Guarda Nacional e o golpe de Estado contra Sacasa, são os marcadores do nascimento do Estado Somozista.
} 
da FSLN, de 1969, e do Programa de la Junta de Gobierno de Reconstrucción Nacional de Nicaragua, divulgado dez anos depois, em junho de 1979, a partir da Costa Rica, pela Junta de Governo encabeçada pela FSLN. É fundamental relacionarmos o programa sandinista à teoria marxista a partir de uma reflexão que aborde a forma com que esta foi incorporada e modificada pelos teóricos da Frente. São nesses documentos que os sandinistas buscaram expor, em linhas gerais, o projeto revolucionário, e como este se reverberaria em propostas de atuação do novo governo nicaraguense, respondendo às ditas "aspirações populares", deixando claras as aspirações democráticas para o novo período de governo que inauguraram em 19 de julho de 1979:

Este Programa de Gobierno que será realizado durante el período provisorio de reconstrucción nacional, sienta las bases de la Nueva Nicaragua y de un Estado democrático, de justicia social, e inicia un proceso revolucionario y nacionalista de profundas transformaciones que dará plena participación a todos los sectores del país en las estructuras políticas, en la reconstrucción nacional, en el desarrollo integral de la nación y en la transformación humanista de la sociedad nicaragüense. (Programa de la Junta de Gobierno de Reconstrucción Nacional de Nicaragua, 1979).

A Revolução Sandinista deve ser vista a partir da conjuntura da segunda metade do século XX, momento em que novos sujeitos reivindicam-se como atores sociais, com demandas de avançar para uma sociedade mais livre, democrática e igualitária. Dessa forma, não podemos compreender o contexto nicaraguense desconectado de uma luta global, mesmo que com a ênfase nas particularidades dos processos latino-americanos, frente aos avanços das democracias liberais do Norte global. Um bom exemplo é como na Nicarágua, tal período é também marcado pelo avanço da luta das mulheres, que desempenharão um papel fundamental no processo revolucionário, organizando-se em torno do feminismo ${ }^{3}$ e de uma agenda política para as mulheres, reivindicando seu papel enquanto sujeito social e político, atuando

3 "o grupo de mulheres que se organizou anteriormente à vitória revolucionária na AMPRONAC tornou-se uma organização popular chamada 'Associação de Mulheres Nicaraguenses Luisa Amanda Espinoza' (AMLAE), homenageando a mulher de mesmo nome que foi a primeira a ser morta pela Guarda Nacional. Elas compreendiam que, além de priorizar as lutas definidas pelo Diretório Nacional da Frente, também deveriam focar em questões relativas aos interesses sociais e econômicos das mulheres, 'as propostas levantadas pela organização das mulheres geralmente desafiavam os preconceitos culturais mais profundos e as práticas discriminatórias, e algumas foram rejeitadas pela liderança da FSLN, pelo bem da 'unidade nacional'. [...] carregado nas palavras da Asociación de Mujeres Nicaraguenses Luisa Amanda Espinoza (AMLAE): 'no hay revolución sin emancipación de la mujer y no hay emancipación de la mujer sin revolución'.” (GONTIJO, 2019, p.14; 121). 
militarmente na luta empreendida pela Frente. As mulheres, assim como a juventude e os povos tradicionais4, adicionam novos elementos ao sentido da democracia sandinista, principalmente ao demandarem o reconhecimento enquanto sujeitos históricos. É a partir desse entendimento, da inclusão e da participação efetiva das mulheres na luta política e nos projetos políticos, que novas questões ganham espaço, contribuindo para o questionamento de discursos clássicos da esquerda marxista. Além disso, segundo Cynthia Chavez Metoyer (1997), o olhar a partir de uma perspectiva de gênero é fundamental ao se analisar o processo sandinista por se tratar de um movimento no qual as mulheres tiveram centralidade e, por isso, qualquer transição para outra forma de governo, como a derrota eleitora em 1990, tem vinculação a questões relativas à demanda por igualdade de gênero ${ }^{5}$.

O revisionismo da teoria marxista, a chamada "crise do marxismo", não era novidade da conjuntura do processo revolucionário sandinista, mas já datava de fins do século XIX, com expressão cunhada por Thomas Masaryk, em 1898, e versando justamente sobre a complexidade e fragmentação do sujeito social, questão que não era levada em consideração pelo marxismo clássico (LACLAU; MOUFFE, 1985) ${ }^{6}$. É posterior a isso, no início do século XX, que o italiano Antônio Gramsci escreve suas obras, estabelecendo-se como um dos mais conhecidos renovadores do marxismo, propondo uma visão culturalista e não-etapista da luta política. Nesse sentido, Gramsci coloca a sociedade civil como central e entende a ideologia como constitutiva das relações sociais. Entendemos aqui o culturalismo gramsciano não como a sobreposição da cultura e das transformações culturais às determinações de classe, mas compreendemos que a questão da cultura e o debate da hegemonia são partes importantes para a consolidação das transformações revolucionárias e as mudanças das relações de classe. Dessa forma, tais categorias são repensadas pelos marxistas e reelaboradas a partir da realidade da América Latina, pelos seus próprios sujeitos. Sendo assim, é necessário tomarmos alguns cuidados para interpretarmos a recepção e influência de Gramsci na Nicarágua e, mais

\footnotetext{
4Aqui damos ênfase à questão das mulheres, primeiro devido à proximidade com o tema, segundo porque a questão feminina, e feminista, se fazem parte constitutiva e fundamental tanto para compreender o desenvolvimento do processo revolucionário sandinista e de sua proposta de democracia, quanto as contradições que desembocaram na derrota da Frente em 1990.

5"a feminist framework is necessary for understanding Nicaragua's transition of state power because women are at the heart of the Nicaraguan revolutionary experience." (METOYER, 1997, p.118).

6 "El problema del marxismo a partir de entonces habrá de ser el de cómo pensar esas discontinuidades y, a la vez, el de las formas de reconstitución de la unidad de los elementos heterogéneos y dispersos." (LACLAU, MOUFFE, 1985, p.36).
} 
especificamente, pelos teóricos do sandinismo. Consideramos fundamental como esse importante teórico marxista foi interpretado na América Latina, e como contribuiu para se repensar a realidade latino-americana. Devemos ressaltar que compactuamos com a ideia da pluralidade da realidade do continente latino-americano, com suas várias historicidades, culturas, línguas, povos etc., o que exige de nós ainda mais cuidado com visões generalizantes e simplistas. Contudo, não podemos perder de vista que havia uma certa articulação entre os debates revolucionários e as esquerdas dos diversos países da América Latina, com diversas trocas propiciadas inclusive a partir dos exílios.

Acerca da relação estabelecida entre as esquerdas latino-americanas e o pensamento gramsciano, diversos autores (ARICÓ, 1988; PORTANTIERO, 1991; MASSARDO, 1997) remeterão ao peruano Mariátegui e aos 20, como um primeiro momento de suposta influência e troca entre ambos continentes. Portantiero (1991, p.155), indo mais além de nossas expectativas, retoma uma visão leninista como importante influência para Gramsci: "entendida ésta como una alternativa para plantear los nexos entre democracia y socialismo a través de una definición del carácter popular de la revolución del proletariado.” Aricó e Massardo, ao debater a perspectiva latino-americana, situarão a década de 1970 como o momento em que se pode perceber "un encuentro relativamente más permanente de Gramsci con las clases subalternas del continente latinoamericano" (MASSARDO, 1997, p.08), tomado de uma força teórica e política a partir da necessidade da esquerda revolucionária de historicizar seus movimentos. Massardo (1997, p.08) também afirma que a incorporação de Gramsci na teoria revolucionária “puede ser considerada como la inspiración de una tentativa de - parafraseando Mariátegui 'latinoamericanizar América Latina'." José Aricó, importante sintetizador do itinerário de Gramsci na América Latina dizia, nove anos antes de Massardo, em 1988, que a publicação de Gramsci em espanhol se espalhou por todo o continente latino-americano na década de 1970 . Mesmo período em que se dá uma maior consolidação da FSLN, na Nicarágua, que levou à vitória revolucionária no fím da década, em 1979. Podemos entender que inserida nessa conjuntura, dificilmente a esquerda sandinista passaria ilesa quanto à importante influência gramsciana. Como veremos, podemos perceber a presença de ideias e vocabulários gramscianos nas teorias sandinistas, principalmente quando estas tratam da necessidade de uma "transformación intelectual y moral", da busca por construir "un orden nuevo". Gramsci também é considerado como um teórico central para esquerda democrática, em que "puede 
afirmarse que las elaboraciones de Gramsci formaran parte de nuestra cultura y constituyen un patrimonio común de todas aquellas corrientes de pensamiento democráticas y reformadoras del continente." (ARICÓ, 1988, p.84).

Do interior da conjuntura latino-americana, Aricó destaca a importância das ideias gramscianas na América Latina a partir do processo cubano, de fundamental influência para os sandinistas da segunda metade do século XX, inserindo tais teorizações em um processo contraditório de avanço de golpes militares no Cone Sul, bem como de mobilização para luta revolucionária em países como Chile e Nicarágua. Segundo ele (1988, p.85), nessa conjuntura, "las ideas de Gramsci contribuyeron primero a nutrir proyectos radicales de transformación, para posibilitar luego reflexiones más críticas y realistas de las razones de una trágica desventura." É também o autor italiano que dará centralidade à ideia do "nacional popular", ponto importante de diversos processos revolucionários latino-americanos que lutavam contra o imperialismo norte-americano - pauta que se destaca no processo sandinista, já que a luta pela soberania nacional e a construção de uma cultura nacional-popular frente ao imperialismo norte-americano eram fundamentais para a consolidação do processo revolucionário e da nova ordem democrática. Assim, a questão da cultura, vinculada ao debate da hegemonia, era fator fundamental para a consolidação da nova ordem estabelecida com a vitória revolucionária da FSLN. Nesse sentido, Aricó conclui que, para Gramsci, é justamente a soma da reforma intelectual e moral, com a crítica ao senso comum e a disputa da hegemonia que daria origem a uma alternativa democrática. Assim:

Aquí la democracia, entendida como la praxis activa de las clases subalternas, surge como algo inseparable del proceso de autoconstitución de los sujetos populares históricos y del socialismo concebido como una amplianción y una profundización del control democrático sobre la existencia social. (ARICO, 1988, p.117).

Apesar do auge do encontro entre a teoria gramsciana e os revolucionários da América Latina ter se dado na década de 1970, ao tentar mapear a chegada dos escritos de Gramsci na América Latina, encontramos suas primeiras publicações em espanhol difundidas na região desde a década de 1950, com importantes referências para sua divulgação, como a revista editada por Aricó, Pasado y Presente, que circulou na década de 1960 e início de 1970. Raúl Burgos (2009) busca, em seu artigo "Gramsci y la izquierda en América Latina”, retomar 
Gramsci no interior do debate da esquerda revolucionária e da academia latino-americana, partindo da visão de Carlos Nelson Coutinho que caracteriza gramsci como "filósofo de la práxis", como "aquel que propone una lectura humanista y historicista del marxismo" (COUTINHO apud BURGOS, 2009, p.20). Apesar de focar principalmente nas discussões empreendidas da Argentina, Brasil e México, reflete brevemente sobre tais implicações na experiência sandinista, além de nos ser útil para localizarmos o processo nicaraguense nas questões em disputa no seio das esquerdas do Sul global. De início, ao retomar a forma como o pensamento gramsciano foi utilizado na Argentina, podemos utilizá-lo para pensar a Nicarágua, principalmente em dois momentos: o início da década de 1960 e a aproximação de Gramsci e Guevara; e na segunda metade da mesma década, quando o debate nacional-popular é empreendido pelo marxista italiano.

Já na década de 1980, destaca a importância do Seminário Morelia, realizado no México e com a participação da diversidade da esquerda latino-americana, encontro facilitado por este país ser reconhecido pelo asilo político dado àqueles militantes reféns das ditaduras instauradas nos países latino-americanos, em sua grande maioria, com apoio dos EUA. Segundo Burgos, esse seminário traça uma nova visão da esquerda latino-americana, assumindo perspectivas que já estavam sendo colocadas em prática na Nicarágua sandinista. Os dois debates principais para nós eram: primeiramente o empreendido no entorno da concepção gramsciana de hegemonia, que seria responsável por uma renovação da teoria revolucionária; em segundo lugar, a discussão de qual seria o sujeito da transformação revolucionária. Aqui, a Revolução Sandinista pode ser inserida na transformação prática da metodologia revolucionária latino-americana, que passa da "lógica del asalto al poder" para a "lógica de la constitución de la hegemonia" ou da “revolución como un proceso". A disputa pelo conceito de democracia é colocada por Burgos também nessa conjuntura da década de 1980, na qual esta deixa de ser compreendida como monopólio do liberalismo e passa a ser retomada historicamente como uma ferramenta revolucionária, reivindicada desde Marx e Engels. Desde o interior da tradição socialista, a democracia seria, em diálogo com a teoria gramsciana, "terreno legítimo de la lucha por la hegemonía de un proyecto socialista" (BRUGOS, 2009, p.27). Em resumo, para o autor, a relação entre a teoria gramsciana, a democracia e o socialismo, na América Latina seria: 
[...] el socialismo como nueva civilización surgida de una transformación global de las relaciones sociales, que tiene fundamento en un proceso de reforma intelectual y moral a partir de la cultura nacional-popular. Este proceso es el proceso de construcción de la base espiritual de masas del movimiento transformador, en el cual el socialismo se encuentra interiorizado en los individuos, lo que permite entender la teoría de la hegemonía como una teoría de la democracia radical. (BURGOS, 2009, p.29).

\section{Democracia y Revolución son, desde siempre, las banderas del pueblo de Sandino $^{7}$}

A Revolução Sandinista destacou-se no cenário mundial como uma importante revolução de esquerda na América Latina, em tempos de Guerra Fria, marcada pela participação dos mais diversos grupos sociais, os quais compreendiam desde membros da elite nicaraguense às organizações trabalhadoras camponesas. A FSLN foi fundada em 1961 sob inspiração da Revolução Cubana (ZIMMERMANN, 2006), tendo dentre seus principais objetivos a derrubada da ditadura familiar dos Somoza, símbolo do imperialismo norte-americano, que durou de 1936 a $1979^{8}$, e que contava com um importante apoio econômico e político dos Estados Unidos. Ademais, a FSLN se propunha a conquistar a autonomia da Nicarágua frente ao imperialismo, em busca da soberania nacional e da independência do povo nicaraguense, por meio da criação de um Estado democrático e da construção do socialismo. Lygia Rodrigues (1996, p.362) reforça que a FSLN "compreendeu e materializou esses desígnios num projeto político cujo eixo, reiterado após a conquista do poder, era garantir a autodeterminação nacional; assegurar o direito de explorar e exercer suas potencialidades históricas e definir sua lógica interna de crescimento." No decorrer do processo de luta contra a ditadura, a FSLN teve papel de destaque, tornando-se hegemônica entre os diversos grupos de diferentes setores sociais que compunham a oposição ao regime somozista, e protagonizaram o movimento de resistência, forjaram a unidade no entorno de um objetivo comum, em um momento de crise revolucionária e de articulação das relações de poder (RODRIGUES, 1996). Posteriormente à vitória revolucionária, em julho de 1979, e à derrocada do governo Somoza, a preeminência da Frente se reafirmou. Segundo Gilles Bataillon (2008),

7CORAGGIO, 1984, p.51.

8 Anastasio Somoza García, Tacho (1936-1956), após seu falecimento sucedido por seu filho Luis Somoza Debayle (1957-1962), René Schick (1963-1966) e Lorenzo Guerrero (1966 - 1967) e, por fim, Anastasio Somoza Debayle (1967-1979). 
Los sucesos de 1979 se desenvuelven según una dinámica militar y diplomática que, en el interior, conduce al derrumbe de la Guarda Nacional y a la subsecuente primacía del FSLN, dando el papel primordial de sus combatientes; y, al mismo tiempo, en el exterior, a la ruptura diplomática de cada vez más países latinoamericanos con el gobierno de Somoza, y al reconocimiento concomitante del gobierno provisional formado por elementos de la oposición. (BATAILLON, 2008, p. 172).

No momento da tomada do poder, o governo revolucionário sandinista possuía mais legitimidade que qualquer outro governo da América Central (ZIMERMANN, 2006), fator fundamental para cumprir com os desígnios democráticos que era uma das bases teóricometodológicas do processo de transformação revolucionária. Mesmo assim, e mesmo cedendo à lógica da democracia representativa a fim de garantir a legitimidade do processo revolucionário frente aos Estados democrático-liberais do Ocidente, não foi o suficiente para se sustentar dentro da lógica das instituições vigentes frente à grave crise econômica que devastava o país e a contraofensiva dos EUA, principalmente por meio da organização e financiamento dos Contra $^{9}$ e do bloqueio econômico imposto pela nação imperialista. Os ataques norteamericanos ao novo governo que se instaurou em 1979 levaram ao endurecimento do regime, além de graves violação aos direitos humanos. Devido a essas diversas dificuldades a FSLN que tinha como candidato à reeleição Daniel Ortega, dirigente histórico da Frente - perdeu as eleições presidenciais de 1990 para Violeta Chamorro, viúva de Pedro Joaquín Chamorro ${ }^{10}$ e líder da União Nacional Opositora (UNO).

No entendimento da ampliação dos sujeitos sociais, históricos e políticos, é importante ressaltar como a Revolução Nicaraguense se destaca pela expressiva participação das mulheres no processo revolucionário. Questões que diziam respeito às mulheres estavam presentes na

9Os Contra eram a oposição armada contrarrevolucionária, que buscavam por fim ao governo revolucionário sandinista instaurado em 1979. Segundo Van Eeuwen (In. ROUQUIÉ, 1994), eram financiados pelos EUA desde 1981, com o presidente Reagan. Foram batizados por Reagan de "combatientes pela liberdad", inserindo-se na política de "guerras de baixa intensidade" do governo norte-americano num contexto de Guerra Fria e de luta contra o comunismo e o marxismo-leninismo. A base principal de atuação e a entrada no território nicaraguense era através da fronteira com Honduras. Apenas 5\% das fileiras contrarrevolucionárias era composta por mulheres.

10 Pedro Joaquín Chamorro foi assassinado pela Guarda Nacional de Somoza em 10 de janeiro de 1978, agravando as tensões que havia na sociedade. Segundo Bataillon (2008, p.155), esse episódio trouxe uma nova interpretação para crise político-social que vivia a Nicarágua, segundo a qual o então regime seria a encarnação da barbárie e a oposição seria o oposto, a civilização. Segundo o autor, foi esse momento que propiciou uma aproximação entre as diversas forças de oposição. 
organização da Frente desde a sistematização do Programa Histórico ${ }^{11}$, publicado em 1969, que já tratava, com importância, da emancipação das mulheres ${ }^{12}$. Além disso, houve forte participação feminina, e feminista, em diversas ações revolucionárias ${ }^{13}$. Van Eeuwen (1994) aponta que nas eleições de novembro de 1984, a FSLN apresentou 34 mulheres candidatas, em um total de noventa, número expressivo até nos dias atuais, mostrando que a atuação feminina também se deu por meio da participação política institucionalizada. Outro papel importante desempenhado pelas mulheres no decorrer da Revolução diz respeito à defesa dos Direitos Humanos. É importante compreendermos essa participação das mulheres dentro de um prisma de luta pela ampliação da "democracia popular", pois a transformação de sujeitos até então considerados subalternos em sujeitos sociais e históricos, é fundamental para a prática democrática que propunham os sandinistas.

A Revolução era chamada de popular pela Frente devido à adesão espontânea da população nicaraguense à luta, a partir de um chamado organizado, ou seja, devido à massiva participação direta do povo na transformação política. Tal diversidade de sujeitos atuando no processo de luta revolucionária é fundamental na busca da Frente pela construção de um conceito central para nossa compreensão do processo sandinista, que Luís Coraggio (1984) chamou de "democracia substantiva". Sua aplicação dependia justamente da ampliação de formas de participação popular. Segundo Luis Coraggio, a Frente adota a "hegemonia popular" ${ }^{\prime 4}$ como central à transição para nova sociedade, na contramão do marxismo clássico etapista, que vinha sendo modificado desde as releituras leninistas. Na Nicarágua, vai-se

11 "Es el reflejo de la interpretación de la realidad social de Nicaragua y la exposición de los postulados fundamentales que guiarían las transformaciones revolucionarias, una vez que el régimen somocista fuera liquidado y el poder del pueblo se convitiera en realidad. [...] El Programa Histórico del FSLN es la ruptura con las viejas concepciones que se mantenían acercade cuál debía ser el camino revolucionario, y un instrumento de lucha donde el pueblo reconoció en cada punto programático la posibilidad de ver realizadas sus reivindicaciones históricas negadas por el poder opresor." Apresentação do Programa Histórico. Disponível em: http://www.fslnnicaragua.com/documentos/historico/index.html. Acesso em: 17 jan. 2018, $12 \mathrm{~h} 48$.

12“VII. Emancipación de la mujer: La Revolución Popular Sandinista abolirá la odiosa discriminación que la mujer ha padecido con respecto al hombre; establecerá la igualdad económica, política y cultural entre la mujer y el hombre".

13Segundo Zimmermann, após a vitória revolucionária três mulheres foram elevadas a Chefes Guerrileiras: Dona María Tellez, comandante da Frente Ocidental, desenvolveu um papel importante na retirada da Guarda Nacional de León; Letícia Herrera; e Mónica Baltodano, figura central do movimento clandestino urbano. Além disso, mais da metade das brigadas alfabetizadoras no campo eram compostas por mulheres, os Comitês de Defesa Sandinista (CDS) eram, em sua maioria, presididos por mulheres e, segundo Santamaría (2005), cerca de 30\% da guerrilha era feminina.

14Povo enquanto detentor do poder hegemônico. 
conformando o desenvolvimento de uma nova correlação de forças sociais que pode ser percebida em um sistema político hegemonizado pelos setores populares. Dessa forma,

[...] como revolución social, a partir de condiciones heredadas muy difíciles, la Revolución Popular Sandinista tiene que ser una revolución de la sociedad civil, y debido a ello, será una profunda revolución política. Aunque el papel del FSLN como conductor revolucionario es innegable, el sujeto de la revolución no está dado de antemano sino que es en sí mismo uno de los objetivos de la Revolución. (CORAGGIO, 1984, p.35).

Assim, a "democracia substativa" de Coraggio, chamada de "democracia popular" pela FSLN, pode ser caracterizada pela ampliação da participação popular, a participação direta da população, a atuação ativa por meio de organizações sociais - com a criação de associações de mulheres, de trabalhadores, de jovens, de camponeses etc. -, em contraposição à forma de democracia estabelecida no Ocidente, conhecida como democracia representativa, ou como podemos chamar, a democracia burguesa. Foi assim, com a participação de uma heterogeneidade de setores da população nicaraguense que a Revolução triunfou em 1979, sob o discurso da autonomia, da hegemonia do povo da Nicarágua e do anti-imperialismo. Retomaram a utopia da Revolução nacional e democrática gestada sob o pensamento de Sandino. Dessa forma, os sandinistas conseguiram unir projetos políticos opostos através da pauta da libertação nacional, buscando reorientar o processo de desenvolvimento do país. As funções políticas de uma revolução que se propunha nacional e democrática se entrelaçaram com a libertação dos povos e oprimidos, das classes exploradas. Assim, o socialismo da FSLN foi construído no decorrer da luta, em que buscaram erigir um Estado democrático e soberano, com as estruturas de poder democratizadas, regidas de acordo com a necessidade das massas organizadas na FSLN. Para Igor Santos García (2019, p.165), a defesa de democracia e do socialismo estavam interligadas no interior da teoria sandinista, apesar de não reforçarem a retórica do socialismo frente ao exemplo do que vivia a vizinha Cuba:

A democracia popular, por exemplo, era usualmente caracterizada como manifestação de um Estado nacional e soberano. Sua natureza de classe, ademais, integrava o discurso em prol da construção do socialismo nicaraguense, de maneira que, segundo o discurso revolucionário, a libertação nacional, a democracia e o socialismo eram conceitos interconectados. [...] Superada a dominação imperialista - libertação 
nacional -, consolidava-se uma alternativa nacional ao modelo político dependente, a democracia popular e direta. [...] Assim, os materiais de propaganda elaboravam um discurso em que a libertação nacional, sustentada politicamente pela democracia revolucionária, caminhava, quase como um prolongamento natural, ao socialismo. (GARCÍA, 2019, p.165).

Nesse sentido da busca por um processo que garantisse a manutenção da ordem democrática e propriamente nicaraguense, é importante destacarmos o distanciamento que os sandinistas tentaram estabelecer em relação ao processo cubano, e de defesa ferrenha do socialismo em seus discursos. Com a ressalva do exemplo e o apoio cubano, que foi fundamental para o desenvolvimento da FSLN, tanto enquanto um movimento político-social, quanto teoricamente, foi Cuba que treinou os militantes da Frente para guerrilha, e que, na década de 1980, compartilharam os trabalhos nas brigas alfabetizadoras nicaraguenses. Contudo, os sandinistas queriam ter autonomia frente ao seu processo político, queriam ser vistos não apenas como uma sombra da Cuba revolucionária. Além disso, a centralidade da democracia entra em conflito com a opção adotada pelos dirigentes cubanos ${ }^{15}$.

Alguns autores, como Matilde Zimmermann e Emír Sader, localizam o processo nicaraguense entre outros dois: a Revolução Cubana de 1959, protagonizada pelos guerrilheiros da Sierra Maestra sob comando de Fidel Castro e Che Guevara"16; e a "via democrática ao socialismo" adotada pela Unidade Popular Chilena, experiência encabeçada por Salvador Allende e materializada em seu governo, entre 1970 e 1973. Apesar de muito destaque ser dado para influência cubana na experiência de luta armada guerrilheira - durante algum tempo com inspiração direta no foquismo de Guevara -, Harry E. Vanden (1997) considera que nas eleições de 1990, parecia que a Frente se aproximava ainda mais da possibilidade de construir a perspectiva da experiência social-democrata chilena, ao darem sentido ao processo eleitoral como uma forma da população nicaraguense optar pela continuidade da construção do socialismo, ou escolher outro regime político ${ }^{17}$. É claro para nós que o debate democrático não

150 debate sobre o que é a democracia é polêmico, sendo discutido por diversos autores, há uma discussão sobre o que seria a democracia para o marxismo e para as esquerdas, em contraposição aos moldes democráticos hegemônicos, que não passariam de uma "falsa democracia burguesa". Para aprofundar tal discussão no interior do debate sandinista, indicamos a dissertação de mestrado defendida por Igor Santos Garcia, em fins de 2019, sob o título "Revolução, democracia e socialismo no discurso político da Frente Sandinista de Libertação Nacional (1969 - 1984)", sob orientação da Profa. Dra. Kátia Gerab Baggio.

16Destacamos também: Camilo Cienfuegos, Vílma Espín, Haydée Santamaría e Célia Sanchez.

17Tradução nossa: "Up to the time of the February election it seemed that the Nicaraguan revolution might be able to build on the experiment with socialist democracy that developed in Chile in the early 1970s. The Sandinistas 
era uma novidade no interior das esquerdas. Desde a década de 1960 que a grande maioria dos países da América Latina viviam regimes ditatoriais e autoritários, fossem eles militares como no cone-Sul, ou familiares como na América Central, apoiados pela potência imperialista norteamericana que, no contexto da Guerra Fria, representava o sistema capitalista. Dessa forma, em primeiro lugar, adotar a retórica da democracia era uma forma de se opor à dominação dos EUA e reafirmar a soberania nacional. Igor García (2019, p.163) afirma que, para a FSLN, "a democracia revolucionária era a manifestação política da soberania nacional, pois substituía um sistema político a serviço do imperialismo - democrático na forma e autoritário no conteúdo". Em segundo lugar, a experiência cubana e a forte repressão que sofria o país, condição explícita no bloqueio econômico decretado pelos EUA, faziam com que a opção declarada pela "ditadura do proletariado" não fosse uma opção adotada pela Frente. A partir dessas considerações -mesmo que fundamentalmente o processo nicaraguense tenha importantes contribuições para a teoria e a prática das esquerdas, os próprios sandinistas reivindicavam as particularidades do processo deste país - inserimos o processo da Revolução Sandinista no entremeio do debate teórico-metodológico e da prática revolucionária desses dois importantes processos latinoamericanos por adotarem a via da luta armada como etapa fundamental do processo insurrecional como única forma de vencer a ditadura somozista, assim como a retórica da defesa da democracia.

Temos de diferenciar a proposta teórica de "democracia popular" defendida pelos sandinistas da democracia burguesa hegemônica no Norte global. Porém, apesar da diferenciação teórica, não podemos perder de vista, e aqui esse ponto é fundamental para nós, as contradições da práxis revolucionária. Para os sandinistas, as eleições eram entendidas como uma das formas de institucionalizar e legitimar parcialmente o processo revolucionário frente às potências estrangeiras, por isso era um dos componentes da democracia proposta, assim como a liberdade de expressão e de organização política. Apesar de defenderem que democracia real seria de fato aquela que ampliaria a participação popular, a opção pela via eleitoral explicita a necessidade estratégica de se submeterem a algumas das práticas da democracia burguesa. Para Igor García (2019, p.109), isso significava "a capacidade da Frente Sandinista de caminhar, através de seu discurso e de sua prática política, entre a democracia 'consensual' [o que aqui

would give an expanded electorate the opportunity to decide if they wanted to continue the process of socialist construction or opt for another type of regime." (VANDEN, 1997, p.52). 
estamos chamando de democracia burguesa], um escudo da revolução, e a democracia popular, base de seu programa revolucionário." Coraggio (1984), afirma que os sandinistas iam além, traçando três principais eixos interdependentes: democracia, economia mista e não-alinhamento. Segundo o autor, a democracia era o conceito-chave do poder da FSLN e da Revolução, apontada como uma alternativa democrática para a construção do socialismo, optando-se pela "hegemonia popular" em contraposição à "tradicional” ditadura do proletariado,

[...] el concepto mismo de legitimidad deberá construirse en base a la realidad específica de una Revolución que avanza simultáneamente en la socialización económica y en la socialización del poder a favor de las mayorías, sosteniendo a la vez un sistema democrático pluralista en lo interno y en sus relaciones internacionales. (CORAGGIO, 1984, p.13).

Nesse sentido, a construção do Estado revolucionário passava pela construção da sociedade civil a partir da criação de novas práticas, instituições e ideologias, disputando as mentalidades. Para isso, partia-se da ideia de que o poder não fora tomado, mas sim estava em construção diária, na busca por novas práticas e na luta contra a hegemonia imperialista. Isso só foi possível por desviarem de uma visão unicamente economicista da forma de organização da sociedade, entendendo que "la alienación de las masas no se deriva mecánicamente de sus condiciones materiales de vida y producción, sino que es producida también por la ausencia de una práctica democrática, y que su liberación requiere avanzar simultáneamente en ambos frentes de transformación" (CORAGGIO, 1984, p.24). Aproximam-se do entendimento de que a questão de classe e da subordinação popular passava pela organização da cultura e das várias instituições presentes na sociedade, o que abre diálogo com ideias referenciadas em Gramsci, na busca por disputar a hegemonia, ou podemos dizer, na construção da contra-hegemonia. Para os sandinistas, vencedores em 1979, a transformação da consciência era parte fundamental e constitutiva do processo revolucionário, a revolução não se resumia à tomada de poder limitada, mas em uma disputa moral, na necessidade de se forjar uma nova consciência social ${ }^{18}$. $\mathrm{O}$ discurso sandinista operava na "lógica da maioria" e pela "hegemonia popular".

18"Pero esa conciencia, que debe ser teóricamente desarrollada y difundida por una clase social a partir de la defensa de sus intereses, no necesariamente -ni mucho menos mecánicamente- se genera en las prácticas recurrentes que se realizan en las diversas instituciones sociales. Se abre entonces la alternativa de que una vanguardia político-ideológica asuma esa "conciencia posible", como sujeto político que se anticipa 
Para Serra (1985), o projeto de "democracia social" sandinista implicava além da economia mista e do não-alinhamento, o baixo controle estatal, a prioridade dos interesses populares, a autodeterminação nacional e o pluralismo político, tudo isso submetido à hegemonia popular. Nesse cenário, para o autor, as eleições de 1984 marcaram uma nova etapa revolucionária, servindo como um processo educativo "para elevar el nível de conciencia cívica y de organización del pueblo" (SERRA, 1985, p.77). Nós tendemos a, de certa maneira, discordar dessa afirmação, pois acreditamos que o uso de mecanismos da democracia burguesa era uma forma dos sandinistas cederem e "mostrarem" ao resto do mundo que compactuavam com o sistema dominante, porém, não era a democracia representativa suficiente para se alcançar a "democracia popular" proposta. Assim como para Gramsci, na Nicarágua sandinista a questão do poder ia para além do Estado e da sociedade política, encontrando-se na sociedade civil e suas instituições, com necessidade de se aprofundar as transformações revolucionárias e democráticas, para que a ideologia dominante da sociedade somozista não se reproduzisse,

[...] mas allá de la elaboración de una constitución se hallan los retos planteados por la construcción de un nuevo estado, la consolidación democrática de las organizaciones de masas, la articulación de doble vía entre el partido de varguardia y las organizaciones populares, el pluralismo dentro del campo democrático. (SERRA, 1985, p.78).

A Frente adotou as palavras de Sandino de "democracia efectiva y justicia social" como carro chefe, com destaque pra participação popular das mulheres, dos adeptos da Teologia da Libertação ${ }^{19}$ e da juventude. Para a FSLN a legitimidade da Revolução se daria principalmente por meio da constituição do "sujeito social da revolução", ou seja, do povo, do seu desenvolvimento enquanto sujeito político. Segundo Coraggio, para avançar a hegemonia popular e minar o que restava da expressão política do capital, seria necessária a Revolução

temporalmente al sujeto histórico, que lucha así, “en representación” de una clase o un campo social.” (CORAGGIO, 1984, p.21).

19A partir do Concílio do Vaticano II em 1962 e da Conferência de Medellín em 1968, parte da Igreja Católica latino-americana começa a romper laços com os regimes oligárquicos tradicionais e busca por novas articulações sociais, privilegiando os setores populares e passando a reconhecer organizações e manifestações religiosas populares. Nesse cenário surge a Teologia da Libertação como um movimento eclesial chamado de cristianismo revolucionário e muitas vezes de "Igreja dos pobres". Segundo Lowy (2016, p.79) é uma reflexão religiosa e espiritual, "admitindo a autonomia da esfera política, ela deixa essas questões para os partidos políticos da Esquerda, limitando-se a fazer uma crítica social e moral à injustiça, a aumentar a consciência da população, a espalhar esperanças utópicas e a promover iniciativas "de baixo para cima". 
Cultural, sendo a cultura o espaço da disputa da hegemonia. A questão da "luta ideológica", da disputa pela hegemonia, da necessidade de se transformar a mentalidade, é central para a Revolução Sandinista. Desde fins dos anos 1960 e início dos 1970, percebemos como as ideias de Gramsci surgem como uma alternativa de projeto revolucionário diante das experiências já mais consolidadas na época, como a soviética e cubana ${ }^{20}$. Apesar da ideia de "hegemonia" remontar à Rosa Luxemburgo, Lênin e outros/as marxistas reconhecidos/as, a visão de Gramsci é inovadora. Para ele, a construção cultural e ideológica é fundamental na construção da sociedade, exercendo um papel coercitivo da classe dominante sob a classe trabalhadora (no capitalismo). A hegemonia, além de uma direção política, é uma direção moral e cultural, fazendo-se necessária a luta ideológica para construção da nova sociedade:

\begin{abstract}
A hegemonia tende a construir um bloco histórico, ou seja, a realizar uma unidade de forças sociais e políticas diferentes; e tende a conservá-las juntas através da concepção de mundo que ela traçou e difundiu. [...] a luta pela hegemonia deve envolver todos os níveis da sociedade: a base econômica, a superestrutura política e a superestrutura ideológica. (GRUPPI, 1978, p.78).
\end{abstract}

Para ele, a ideologia se manifesta em todas as instituições da sociedade, tais como a escola, a Igreja, na arte, nas atividades econômicas, em todas as manifestações sociais sendo elas individuais ou coletivas. Nesse sentido, a relação entre a sociedade civil e a sociedade política $^{21}$ é fundamental para se compreender a construção da hegemonia,

A hegemonia é a capacidade de direção, de conquistar alianças, capacidade de fornecer uma base social ao Estado proletário. Nesse sentido, pode-se dizer que a hegemonia do proletariado realiza-se na sociedade civil, enquanto a ditadura do proletariado é a forma estatal assumida pela hegemonia. (GRAMSCI, apud GRUPPI, 1978, p.5).

\footnotetext{
20Não desconsideramos a importância da Revolução Cubana para o desenrolar da Revolução Nicaraguese, pelo contrário, a vitória e exemplo cubano foram fundamentais, contudo existem algumas divergências entre os dois projetos revolucionários que não devem ser ignorados.

21 "Gramsci, ao contrário de Lênin, situa a essência na luta contra a classe dirigente na sociedade civil. Para ele, o grupo que controla é hegemônico, e, ao alcançar a conquista as sociedades políticas, essa hegemonia é coroada, passando a estender-se ao conjunto do Estado, que contempla a sociedade civil e a sociedade política. $\mathrm{Na}$ hegemonia gramsciana há uma primazia da sociedade civil em relação à sociedade política, ao contrario da leninista que inverte, dando primazia à sociedade política em relação à sociedade civil.” (MACIEL, 2008, p.32).
} 
Assim, o conjunto de valores culturais presentes em uma sociedade "pode impregnar, penetrar, socializar e integrar um sistema social, o qual, por sua vez, só pode ser considerado integrado quando estiver solidificado em um sistema hegemônico, o qual deve ser dirigido pela classe fundamental confiada aos intelectuais" (MACIEL, 2008, p.37). Para Gramsci,

\begin{abstract}
A supremacia de um grupo social se manifesta de duas maneiras, como 'domínio' e como 'direção intelectual e moral'. Um grupo social é dominante dos grupos adversários que tende a 'liquidar' ou submeter mesmo que com a forma armada e é dirigente dos grupos afins e aliados. Um grupo social pode e deve ser dirigente já antes de conquistar o poder governativo (esta é uma das condições principais para a própria conquista do poder); depois, quando exercita o poder e na medida em que o mantém fortemente em suas mãos, torna-se dominante, mas deve continuar sendo 'dirigente'. (GRAMSCI apud MACIEL, 2008, p.22).
\end{abstract}

Dessa forma, aproximamos a visão da Frente da "democracia social” por defenderem a "luta ideológica" como essencial para a disputa da sociedade, com a preocupação em fazer a disputa revolucionária também no campo das mentalidades. Com isso, buscavam estabelecer a hegemonia do povo nicaraguense contra, principalmente, o imperialismo norte-americano marcado nas práticas e nos discursos do somozismo que dominou por décadas a cultura nicaraguense, colocando, em contraposição ao somozismo, a cultura popular como a verdadeira cultura nacional. Para a FSLN, na luta contra a hegemonia imperialista, dar-se-ia ênfase ao nacional-popular que, segundo Aricó (1988, p.110), tem um papel central do pensamento de Gramsci, "en la medida que remite al problema general de las relaciones entre intelectuales y pueblo y de sus consecuencias en términos de la constitución de la nación y de la transformación socialista.”. Ou seja, a construção de uma cultura propriamente nicaraguense (para os sandinistas), ou latino-americana (para Gramsci), seria fundamental para construção do socialismo e o enfrentamento à dominação capitalista, agente na figura do imperialismo norteamericano.

Desde o Programa de Governo proposto pela Junta estabelecida após o triunfo da revolução armada, em 1979, faz-se presente no discurso sandinista a defesa da democracia e da hegemonia popular, com grande centralidade e como as bases nas quais se organizaria o país. Esse documento visava traçar as principais vias de ação e as transformações que pretendiam empreender os/as vitoriosos/as, encabeçados/as pela FSLN. Já na introdução, reforçam como 
foi necessária a participação de todos os setores do país na luta contra a ditadura, dando ênfase ao caráter plural, popular e democrático da luta revolucionária. Tal participação é eixo fundamental para a "democracia popular" proposta pelos sandinistas, pois sua base é justamente a ampla e direta participação da sociedade na política, que se daria principalmente por meio das organizações civis, nesse sentido, defendiam a "plena participación a todos los sectores del país en las estructuras políticas, en la reconstrucción nacional, en el desarrollo integral de la nación y en la transformación humanista de la sociedad nicaragüense". Assim, o Programa de Governo buscava estabelecer as bases da "Nueva Nicaragua" no "Estado democrático, de justicia social".

O primeiro ponto do documento, intitulado de "Area Politica", traça as bases para a nova política nacional. No item 1.1 definem a prioridade do novo governo estabelecida como a "instauración de um régimen de democracia, justicia y progreso social”. Reforçam a garantia de plenos direitos de participação política e sufrágio universal a todos/as os/as nicaraguenses, a fim de garantir a democracia efetiva, a justiça e o progresso social. Além disso, reiteram a livre organização partidária e de organizações populares - desde que não busquem restabelecer o somozismo - como forma de ampliar a participação popular. Esse último ponto é fundamental, pois a massiva participação popular em organizações civis era uma das principais estratégias de ampliação da participação política na "democracia popular", diferente da esporádica e indireta atuação política na democracia representativa. Assim, ao assumirem na "Bases para la organización del Estado" um compromisso com as eleições, permanecendo a Junta de Gobierno apenas para "sentar las bases de un genuíno desarollo democrático de Nicaragua, sustentado en una amplia participación popular y en la aplicación prática de los conceptos y propósitos señalados en punto 1.1", reforçamos tal postura como ponto de mediação da Frente a fim de se legitimarem frente às democracias burguesas. Aqui também defenderão o não enfrentamento direto com a burguesia nacional, mantendo a ampla representatividade das aspirações políticas de diferentes grupos no poder legislativo, com um Conselho de Estado que incluía diferentes forças políticas, econômicas e sociais. Pensava-se que estes seriam vieses possíveis de manterem o poder político, incluindo os grupos dissidentes e neutralizando a oposição. Além dessas questões, afastavam-se de caracterizações autoritárias ao defenderem os direitos fundamentais de liberdade de expressão, livre-organização política, social e religiosa. $\mathrm{O}$ discurso sandinista presente no Programa considerava que: 
[...] se abrirá a todos los nicaragüenses la possibilidad real para el mejoramiento de la calidad de la vida, mediante el establecimiento de una politica que tienda a erradicar la desocupación y que haga efectivo el derecho a la vivienda, la salud, la seguridad social, el transporte colectivo eficiente, la educación, la cultura, el deporte y la sana diversión. (Programa de la Junta de Gobierno de Reconstrucción Nacional de Nicaragua, 1979)

Nessa perspectiva, além da cultura, que já mencionamos, a educação desempenhava um papel fundamental para o processo de transformação da sociedade, orientando a população em um sentido crítico e libertador, indo de acordo com a visão de Gramsci acerca da centralidade da educação na disputa pela transformação das mentalidades. Inclusive, investem na "educação libertadora" para adultos "con el fin de incorporarlos plenamente al proceso de recostrucción y desarrollo nacional". Não é à toa que as campanhas de alfabetização, inspiradas e apoiadas pelo governo cubano, foram parte vitoriosa da Revolução Sandinista. Na disputa cultural "se estimulará en todas sus expresiones la producción literaria, artística, artesanal y folklórica, de la manera que se pueda consolidar una verdadera cultura popular nicaragüense, y se trabajará para la recuperación de los valores culturales nacionales", visando à construção do nacionalpopular. A essas questões levantadas se somaria a autonomia dos municípios a partir de eleições de "autoridades livres". Tais posições definidas no documento, e muitas outras, seriam garantidas por um exército nacional que teria como princípio fundamental a defesa do processo democrático, além da soberania e independência da nação.

Desde o Programa Histórico, de 1969, divulgado dez anos antes do Programa de Governo, tinha-se estabelecida a demanda pela ampla participação popular, que posteriormente se desenvolve na perspectiva da "democracia popular". Esse documento versa sobre um governo popular que "permita la plena participación de todo el pueblo". Também nele já é possível identificarmos a importância da cultura e da alfabetização, como fundamentais para a expulsão da chamada pelos sandinistas, cultura neocolonial. Definem ser o povo o "auténtico creador y forjador de nuestra cultura". Como vimos, parte da "democracia popular" defendida pelos sandinistas depende fundamentalmente, além do desenvolvimento da cultura nicaraguense, da ampliação da participação política, dos diversos setores populares compreendidos enquanto sujeitos sociais, culturais e políticos. Dessa forma, o Programa Histórico já contava com a defesa de povos e sujeitos até então ignorados pelo poder público - 
e pela história. Seria o caso da parte VI, "Reincorporación de la Costa Antlántica", em defesa dos povos indígenas dessa região, de sua cultura e autonomia frente ao imperialismo "yanque"; já no ponto VII tratam da "Emancipación de la mujer", compreendendo que "la Revolución Popular Sandinista abolirá la odiosa discriminación que la mujer ha padecido con respecto al hombre; establecerá la igualdad económica, política y cultural entre la mujer y el hombre.”. Muito do ponto relativo às mulheres se dedica à questão da maternidade, o que poderia ser considerado insuficiente para as feministas na atualidade, contudo, naquele momento a emancipação da mulher era pensada junto da responsabilização, pelo Estado, das crianças, de sua educação e das tarefas de cuidado, para que as mulheres pudessem elevar "el nivel político, cultural y vocacional de la mujer, mediante su participación en el proceso revolucionario.”, ou seja, para garantir a participação política das mulheres, entendidas como sujeito.

No que diz respeito ao conflito entre a compreensão de democracia pelos sandinistas e a democracia burguesa, ou liberal, em curso no Norte global, também encontramos no Programa Histórico manifestação da crítica sandinista ao modelo liberal, ao firmarem apoio ao movimento negro e do povo estadunidense que, de fato, quisessem alcançar a "auténtica democracia y la igualdad de derechos.". Contudo, como dissemos, apesar de todos os esforços, a FSLN acaba cedendo ao modelo da democracia representativa, o que, segundo Harry E. Vanden (1997), foi uma forma de tentar legitimar o governo sandinista aos olhos das democracias liberais do Ocidente. Apesar disso, o fato de a primeira eleição, realizada em 1984, e a posterior, de 1990, terem tido uma ampla participação popular, mesmo com o voto não obrigatório, deu esperanças de uma possível consolidação de um tipo de prática democrática o que seria significativo para um país que até meados do século XX só tinha tido experiências autoritárias em sua história -, o que para Vanden se confirmou em uma desilusão devido à baixa participação da população nas eleições posteriores a Violeta Chamorro, em 1995. O autor define como imaturo o sistema democrático nicaraguense, pelo menos quando avaliado a partir dos termos da democracia representativa/liberal/burguesa. Muito desse eventual fracasso da continuidade da experiência democrática seria fruto da cultura política que permaneceu dominante: autoritária, elitista e personalista. Além da permanente intervenção estrangeira que, dentre as contraofensivas ao governo sandinista, investiu um grande montante em dinheiro para garantir a vitória da UNO nas eleições de 1990, assegurando a retirada dos sandinistas das esferas 
de poder e o estabelecimento de uma política neoliberal na Nicarágua, assim como havia feito no restante do continente latino-americano.

\section{Conclusão: Revolución Popular Sandinista ${ }^{22}$ ?}

Nas discussões propostas, reforçamos a centralidade da questão democrática para o novo Estado que se gestava na Nicarágua e para construção da "nova sociedade" proposta pelos sandinistas. Contudo, se nos furtarmos de um olhar mais detalhado para a prática cotidiana da revolução, não conseguiremos notar as contradições e desafios da práxis. A derrota sandinista nas urnas em 1990 nos mostra como a Revolução falhou em alguns aspectos e/ou como a disputa ideológica pela hegemonia não foi vitoriosa. Os críticos do processo sandinista afirmarão que a única prática realmente democrática do Estado sandinista e da FSLN foi a aceitação da derrota nos anos 1990, o que podemos enquadrar em um olhar que parte de uma perspectiva da democracia representativa. Ou seja, podemos considerar que, ao dar mais centralidade à via eleitoral, a Frente acaba cedendo à estrutura convencional da democracia burguesa, divergindo da estratégia e da teoria revolucionária que impulsionou a trajetória dos sandinistas até 1983. Para David Close (2016, p.07), nos anos 1990, ao reconhecer a derrota a FSLN mostrou que aprendeu as normas da democracia constitucional, hegemônica no Ocidente, marcando, pela primeira vez na história do país, que uma administração pode ceder o poder político de maneira pacífica a seus oponentes ${ }^{23}$. No discurso de derrota em 27 de fevereiro de 1990, Daniel Ortega, então presidente e candidato à reeleição pela FSLN, reforça a vitória sandinista pelo caráter democrático e de autodeterminação nacional:

Considero que ése es en este momento histórico el principal aporte que los sandinistas, que los revolucionarios nicaragüenses le estamos haciendo al pueblo de Nicaragua, es decir, garantizar un proceso electoral limpio, puro, que aliente aún más nuestra conciencias y alumbre, como este sol que nos alumbra hoy, hacia la consolidación de la democracia, hacia la consolidación de la economía mixta, de una Nicaragua libre, independiente y democrática en paz, no intervenida por potencia extranjera laguna y en donde todos los nicaragüenses seamos capaces de demostrarle al mundo que

22 "Revolução Popular Sandinista" é a forma como os próprios sandinistas utilizavam para se referir à Revolução Nicaraguense.

23Tradução nossa: "the FSLN showed that it had also learned the norms of constitutional democracy by recognizing electoral defeat. This marked the first time in the country's history that an administration had surrendered power peacefully to its opponents." (CLOSE, 2016, p.07). 
podemos convertir en realidad esos sueños, esas esperanzas. (Dicurso del presidente Daniel Ortega - Manágua, 27 de febrero de 1990).

Após ter vencido as eleições presidenciais em 1984, o governo da FSLN adiantou as eleições de 1990 de novembro para fevereiro do mesmo ano. Esse adiantamento teve como causa a crise que se vivia no país, o que podemos compreender como certa permanência da ingerência norte-americana na política nicaraguense. Nesse momento, assolava a crise econômica na América Central, provocada pelo bloqueio imposto pelos Estados Unidos e pela ofensiva contrarrevolucionária financiada pelos mesmos, o que, para Vanden (1997), justifica a dificuldade e falta de preparo do governo sandinista em conciliar de maneira consistente todos estes problemas com o modelo de democracia e de desenvolvimento humano que a revolução traçara em $1979^{24}$. Além disso, o governo sandinista vinha sendo denunciado por uma série de violações dos direitos humanos, imerso em um cenário de tensão e guerra civil, deslegitimando o regime dentro e fora da Nicarágua. Muitas deficiências foram percebidas pelas mulheres no que se refere à década de governo revolucionário. Em suas críticas, ressaltavam que o discurso de igualdade de gênero e de participação efetiva das mulheres no Estado e na sociedade nicaraguense não estava de fato sendo colocado em prática como política do governo. Em contrapartida, a direção sandinista buscava justificar que, em meio ao bloqueio econômico e a guerra contrarrevolucionária, outras questões tiveram de sair do espectro de prioridades. Isso sem entrarmos com detalhes na escassez, ou ausência, de políticas do governo da Frente em relação aos povos indígenas do território nicaraguense, principalmente aqueles que vivem na região Leste do país.

Para Silke Heumann (2014, p.290), a Revolução Sandinista teria sido, a princípio, não apenas o símbolo da democracia, mas também da igualdade de gênero ${ }^{25}$ devido à participação das mulheres na luta armada, no interior da FSLN e no governo revolucionário. Apesar de compreender que havia motivos para que se acreditasse que a revolução caminhava de fato para transformações nas relações sociais e de gênero, a autora discorda que isso tenha se

24Tradução nossa: "The result was that virtually all levels of government and party were not prepared (or predisposed) to deal with the magnitude of the economic problems that befell Nicaragua (because of the war and the embargo) in ways that were consistent with the form of democracy or the model of humane development that the revolution had set as its goals in July 1979." (VANDEN, 1997, p.52-53).

25Tradução nossa: "The revolution became not only a symbol of democracy but also of gender equality." 
transformado em uma realidade. Segundo ela, houve um disciplinamento das feministas pela direção da FSLN, que as pressionava para que deixassem as reivindicações relativas a agenda de mulheres num segundo plano, em prol da defesa da revolução, ameaçada pela crise econômica e pela contraofensiva dos EUA. A autora vai além ao afirmar que a Frente chegou a adotar uma postura antifeminista, principalmente no que diz respeito a questões reprodutivas e de liberdade sexual. Apesar de concordarmos com Heumann no que diz respeito à insuficiência da consolidação da democracia e de políticas de gênero pelos sandinistas, e de ressaltarmos as dificuldades da atuação das mulheres, tanto de garantirem um lugar de proeminência no interior da FSLN e do governo, reforçamos a importância da agenda feminista no interior da Frente e da centralidade do processo sandinista ao colocar as mulheres como sujeitos fundamentais, quanto na luta política, participação fundamental para se alcançar a democracia plena. A intelectual nicaraguense e sandinista Gioconda Belli (2010) reforça essa crítica no que se refere às mulheres, afirmando que o governo da Frente, comandado pelos irmãos Ortega, teria subestimado o papel das mulheres e relegado-as a "tarefas acessórias no Estado sandinista" (GONTIJO, 2019, p.111). Não nos alongaremos aqui a respeito do debate da participação das mulheres e do efetivo compromisso do governo sandinista com a igualdade de gênero, por não se tratar do foco deste trabalho. Nesse sentido, ampliamos tal perspectiva para uma importante crítica feita a prática democrática da Frente, justamente por essa não inclusão real de atores sociais e sujeitos históricos emergentes, assim como de suas agendas. Na lógica da construção de uma “democracia popular", esta dependeria propriamente da incorporação destes sujeitos. Uma das críticas de Dirk Kruijt (2009) vai nesse sentido. Segundo o autor, a FSLN não integrou de fato a população indígena, principalmente os povos da costa Atlântica. Pelo contrário, teriam buscado a “integración e asimilación forzada de esos pueblos al modo de pensamiento sandinista, [o que] creó entre un amplio sector de la población rural un sentimiento de alienación tan intenso que muchos de ellos terminaron sumándose a la 'Contra'.” (KRUIJT, 2009, p.192). Esses fatores, que contribuem para não consolidação da democracia proposta pelos sandinistas, também teriam sido fundamentais para a derrota da Frente em 1990. Kruijt chega a afirmar que o processo nicaraguense foi uma "Revolução sem transformações revolucionárias", por ter cedido ao status quo da democracia burguesa.

Nesse sentido, quais foram de fato as transformações na cultura política nicaraguense que permaneceram após a derrota sandinista nas urnas? Qual percepção de democracia 
permaneceu vigente? Para David Close (2016), já a segunda parte do governo da FSLN, de 1984 a 1990, com Daniel Ortega à frente, havia deixado clara a tradição caudilhista da Nicarágua, deixando fora de tal tradição política apenas o primeiro período de governo da Frente, com a junta de governo entre 1979 e 1984, e o governo de Viole Chamorro, entre 1990 e 1996. Ressalta que ainda é incerto o caminho da Nicarágua para uma democracia constitucional moderna, distante de romper os laços com políticas e práticas paternalistas. Para Secundino Marrero (1991), a Constituição promulgada pelos sandinistas 1987 já se enquadrava a tradição liberaldemocrática ao definir como regime político a democracia representativa, também não a qualifica como socialista, apesar de "socialmente avançada". Seguindo a perspectiva defendida por David Close (2016), a Nicarágua tem uma história marcada mais pelo autoritarismo que pela democracia e, apesar da esperança da democracia ter se manifestado - após séculos de ditaduras e dominação estrangeira -, somente em 1979 com a vitória da FSLN, o atual governo da Frente se manifesta na contramão dessa renomada evidência histórica. As críticas ao sandinismo continuaram, e estão presentes até hoje, devido à volta de Daniel Ortega e da FSLN ao poder em 2006, reeleito em 2011 e 2016, com a instauração de um governo com traços de autoritarismo, o que reforça a teoria da ausência de uma tradição democrática na Nicarágua.

Frente aos desafios e contradições históricas da Nicarágua, nos anos 1990, muitos militantes e dirigente históricos romperam com a Frente, culminando na criação do Movimiento Renovador Sandinista (MRS), fundado oficialmente em 21 de maio de 1995, data de nascimento de Sandino. Em sua "breve história" justificam a cisão devido às "contradicciones sobre la política y la acción del partido, en relación a la democracia interna, la lucha política y social y las reformas constitucionales, en clara oposición a la creciente tendência caudillista de Daniel Ortega" ${ }^{26}$. Para Vanden, desde as eleições de 1990, muitos daqueles/as que optaram por votar na UNO já estavam desiludidos com a Frente por uma suposta perda de contato real com o povo, alegando que estavam governando de cima para baixo e abandonando sem necessariamente corresponderem as demandas populares. Assim, aqueles/as que rompem com a FSLN, reforçam que se fundam sobre os princípios sociais e democráticos, fazendo duras críticas às posições adotadas pela Frente e seus dirigentes. Para finalizar, gostaríamos de partir de uma reflexão

26< http://partidomrs.org/index.php/partido-mrs/breve-historia $>$ Acesso em: 25 jan. 2018, 12 h07. 
provocada por Pierre M. LaRamée e Erica G. Polakoff (1997, p.195), segundo os quais, apesar das contradições e difículdades,

[...] a revolução criou a possibilidade das pessoas tomarem consciência de sua identidade social, incluindo seus direitos enquanto cidadãos e suas responsabilidades enquanto atores sociais engajados no processo de fazer sua própria história. [...] a revolução também providenciou ao povo a consciência de que a vida econômica e social podem ser organizadas de outra forma, sendo eles mesmos capazes de fazer a transformação social. (LARAMÉE; POLAKOFF, 1997, p.195). ${ }^{27}$

Concluímos que, apesar de todas as incongruências, por mais que tenham encontrado diversos embates no momento de colocar em prática a visão de “democracia popular" defendida, a Frente desempenhou um papel importante, propondo uma prática revolucionária que até então não tinha sido visto na América Latina - nem com a Revolução Cubana em 1959, nem com o Chile de Allende, nos início dos anos 1970. Ressaltamos como os ideais e o projeto desenvolvido na Nicarágua sandinista não se encontravam apartados do debate da época e das influências de importantes teóricos do marxismo. Assim como não estavam alheios aos outros acontecimentos e às interferências externas ao projeto em curso de 1979 a 1990.

\section{Referência bibliográfica:}

\section{Fontes:}

Dicurso del presidente Daniel Ortega - Manágua, 27 de febrero de 1990. Disponível em: http://publicaciones.sodepaz.org/images/uploads/documents/revista002/08 discursodanielorte ga.pdf Acesso: 25 jan. 2018, 11h43;

Programa Histórico del FSLN (1969). Disponível em: <http://www.fslnnicaragua.com/documentos/historico/index.html> Acesso: 17 jan. 2018, 12h48;

Programa de la Junta de Gobierno de Reconstrucción Nacional de Nicaragua (1979). Disponível em: < http://sajurin.enriquebolanos.org/vega/docs/Programa\%20de\%20Gobierno.pdf $>$ Acesso: 17 jan. 2018, 12h53.

27Tradução nossa: "[...] the revolution created the possibility for people to become conscious of their social identities, including their rights as citizens and their responsibilities as social actors engaged in the process of making their own history. [...] the revolution also provided people with the knowledge that social and economic life can be organized differently and that they themselves are capable of bringing about social change." 


\section{Bibliografia:}

ARICÓ, José. La cola del diablo: itinerario de Gramsci en América Latina. Buenos Aires: Pontosur, 1988;BELLI, Gioconda. El país bajo mi piel - memorias de amor y guerra. Santiago: Seix Barral, 2010.

BATÁILLON, Gilles. Génesis de las guerras intestinas en América Central (1960-1983). México: FCE, 2008.

BELLI, Gioconda. El país bajo mi piel - memorias de amor y guerra. Santiago: Seix Barral, 2010.

CLOSE, David. Nicaragua: navigating the politics of democracy. Boulder, Colorado: Lynne Rienner Publishers, Inc., 2016.

CORAGGIO, José Luis. Nicaragua: revolución y democracia. Manágua: Editora Línea, 1984.

GARCIA, Igor Santos. Revolução, democracia e socialismo no discurso político da Frente Sandinista de Libertação Nacional (1969-1984). Dissertação (Mestrado). Kátia Gerab Baggio, orientadora. Universidade Federal de Minas Gerais, Belo Horizonte, 2019, $194 \mathrm{f}$.

GONTIJO, Stella Ferreira. "Hasta que seamos libres": feminismo e Revolução Sandinista nas obras de Gioconda Belli (1972 - 1993). Dissertação (Mestrado). Elisa de Campos Borges, orientadora. Universidade Federal Fluminense, Niterói, 2019. 209 f. Disponível em: https://www.historia.uff.br/stricto/td/2361.pdf.

GRAMSCI, A. Cadernos do cárcere. Rio de Janeiro: Civilização Brasileira, 2000-2006, V. 3, p. 11 a 110.

GRUPPI, Luciano. O conceito de hegemonia em Gramsci; trad. Carlos Nelson Coutinho. Rio de Janeiro, Edições Graal, 1978.

HEUMANN, Silke. "Gender, Sexuality, and Politics: Rethinking the Relationship Between Feminism and Sandinismo in Nicaragua" IN: Social Politics, Vol. 21(2), p.290-314, 2014, Disponível em: http://dx.doi.org/10.1093/sp/jxu004.

INVERNIZZI, Gabriele. Sandinistas. São Paulo: Brasiliense, 1985.

LaRAMÉE, Pierre M.; POLAKOFF, Erica G. "The evolution of the popular organizations in Nicaragua." In.: PREVOST, Gary; VANDEN, Harry E. (Org.). The undemining of the Sandinista Revolution. Nova Iorque: Palgrave Macmillan, 1997, p. 141 - 206.

LOWY, Michael. O que é Cristianismo da Libertação: religião e política na América Latina. São Paulo: Editora Fundação Perseu Abramo; Expressão Popular. 2a edição, 2016. 
MACIEL, Maria Helena Ribeiro. "Origem e evolução do conceito de hegemonia"; "Hegemonia em Gramsci”. In. Hegemonia, ajuste neoliberal e ensino superior no Brasil. João Pessoa, 2008, p. $22-44$.

MARRERO, Secundino Gonzales. "La transición a la democracia en Nicarágua". In.: Revista de Estudios Políticos. Nueva Epoca, v.74, out-dez 1991, p.449-469.

MASSARDO, Jaime. "La recepcion de Gramsci en America Latina: cuestiones de orden teorico y político". In.: Centro de Estudios Miguel Enriquez; Archivo Chile, 1997, 25p.

METOYER, Cynthia Chavez. "Nicaragua's transition of state power: trought feminist lenses." In.: PREVOST, Gary; VANDEN, Harry E. (Org.). The undemining of the Sandinista Revolution. Nova Iorque: Palgrave Macmillan, 1997, p. $114-140$.

MIRES, Fernando. La rebelión permanente. Las revoluciones sociales en América Latina. México: Siglo XXI Editores, 2001.

NETTO, João Paulo. Nota sobre o marxismo na América Latina. Disponível em: $<$ http://marxismo21.org/wp-content/uploads/2012/07/O-marxismo-na-America-Latina-JPNetto.pdf $>, 2012,23 p$.

PONCELA, Anna María Fernández. "Nicaragua: revolución popular y elecciones democráticas". In: Dimensión Antropológica, ano 16, vol.46, maio/agosto 2009, p.141 - 180.

PORTANTIERO, Juan Carlo. “Gramsci en clave latinoamericana”. In.: Nueva Sociedad. n.115, setembro-outubro, 1991, p. 152-157.

KRUIJT, Dirk. Guerrilla: guerra y paz en Centroamérica. Guatemala: F \& G Editores, 2009.

RODRIGUES, Lygia. "O Sandinismo e a Revolução Nacional e Democrática na Nicarágua". In: DAYRELL, Eliane Garcindo; IOKOI, Zilda Grícoli. América Latina Contemporânea: desafios e perspectivas. Rio de Janeiro: Expressão e Cultura, 1996.

ROUQUIÉ, Alain. “Indroducción”. Las fuerzas politicas en América Central. México: Fondo de Cultura Económica, 1994.

SADER, Emir. Cuba, Chile, Nicarágua: socialismo na América Latina. São Paulo: Atual, 1992.

SANTAMARÍA, Gema. Alianza y autonomia: las estratégias politicas del movimiento de mujeres en Nicaragua. 2005. Disponível na internet: http://www.movimientoautonomodemujeres.org/archivos/27.pdf .

SERRA, Luis. "Democracia y Revolución en Nicaragua". In. Encuentro: Revista Académica de la Universidad Centroamericana, n.23. 1985, p.70- 79.

VAN EEUWEN, Daniel. "Nicarágua”. In: ROUQUIÉ, Alain. (coord.). Las fuerzas políticas en América Central. México: Fondo de Cultura Económica, 1994. 
VANDEN, Harry E. "Democracy derailed: The 1990 elections and after". In.: PREVOST, Gary. VANDEN, Harry E. (Org.). The undemining of the Sandinista Revolution. Nova Iorque: Palgrave Macmillan, 1997, p.45-73.

ZIMMERMANN, Matilde. A Revolução Nicaraguense. São Paulo: Editora UNESP, 2004. 